\title{
Modern concepts in facial nerve reconstruction
}

\author{
Gerd F Volk, Mira Pantel, Orlando Guntinas-Lichius ${ }^{*}$
}

\begin{abstract}
Background: Reconstructive surgery of the facial nerve is not daily routine for most head and neck surgeons. The published experience on strategies to ensure optimal functional results for the patients are based on small case series with a large variety of surgical techniques. On this background it is worthwhile to develop a standardized approach for diagnosis and treatment of patients asking for facial rehabilitation.

Conclusion: A standardized approach is feasible: Patients with chronic facial palsy first need an exact classification of the palsy's aetiology. A step-by-step clinical examination, if necessary MRI imaging and electromyographic examination allow a classification of the palsy's aetiology as well as the determination of the severity of the palsy and the functional deficits. Considering the patient's desire, age and life expectancy, an individual surgical concept is applicable using three main approaches: a) early extratemporal reconstruction, b) early reconstruction of proximal lesions if extratemporal reconstruction is not possible, c) late reconstruction or in cases of congenital palsy. Twelve to 24 months after the last step of surgical reconstruction a standardized evaluation of the therapeutic results is recommended to evaluate the necessity for adjuvant surgical procedures or other adjuvant procedures, e.g. botulinum toxin application. Up to now controlled trials on the value of physiotherapy and other adjuvant measures are missing to give recommendation for optimal application of adjuvant therapies.
\end{abstract}

\section{Introduction}

Although peripheral facial palsy is the most common pathology of the cranial nerves with an incidence ranging from 20 to 30 cases per 100.000 people per year, only a minority of the patients need a surgical treatment. During the acute phase of the palsy the indication for surgery is less dependent on the aetiology, but more on the individual chance of spontaneous and good functional recovery. In the chronic phase, surgery may be indicated in patients without or with unsatisfactory recovery, and in patients with defective healing. The appointed causes are viral infections such as reactivation of latent herpesvirus infection, trauma, iatrogenic injury, inflammatory affections of the middle ear, metabolic diseases and tumours affecting the facial nerve.

With $60 \%$ to $75 \%$ the major cause for facial palsy is idiopathic paralysis or Bell's palsy. $70 \%$ to $90 \%$ of patient with Bell's palsy recover completely, depending of an early start of steroid medication [1]. In contrast, in Ramsay-Hunt-Syndrome caused by reactivation of herpes zoster, the probability of complete recovery drops to

\footnotetext{
* Correspondence: orlando.guntinas@med.uni-jena.de

* Correspondence: orlando.guntinas@med.uni-jena.de
Department of Otorhinolarnygology, University Jena, Lessingstrasse 2, D07740 Jena, Germany
}

$50 \%$. Patient and treating physician should be aware, that many patients will need conservative and/or surgical treatment later on for defective healing.

Cholesteatoma of the middle ear and schwannomas of the facial or the vestibular nerve are less common causes of facial palsy, either by direct affection or iatrogenically during ear, parotid or skull base surgery. Here, as well as in trauma cases, mainly caused by temporal bone fractures or facial injuries due to traffic accidents or capital crimes, immediate or early surgical reconstruction might be indicated [2]. Indication for surgery is depending on the severity of the nerve lesion, i.e. blunt trauma leading to nondegenerative neuropraxia will not need surgical reconstruction, whereas disruption leading to degenerative neurotmesis will need surgery. Finally, any tumour in the course of the facial nerve from the brainstem to the periphery can cause facial palsy or surgical treatment of the tumour might be the reason for facial palsy. In such circumstances, typically surgery of the primary disease is combined with surgical reconstruction of the facial nerve [3].

\section{Definitions and classification}

The term facial palsy summarizes incomplete loss (paresis) as well as complete loss (paralysis) of facial nerve 
function. The distinction is very important as the indication for surgical reconstruction in patients with incomplete facial palsy has to be proven much more critically. On the other hand, reconstruction in case of a complete functional deficit is more complex. Permanent facial palsy and non-transient functional deficits are the main indication for surgical reconstruction of facial nerve function.

Depending on the localisation of the lesion site, peripheral facial nerve lesion is separated from central facial nerve lesion: in peripheral palsy the facial nerve fibres or the motoneurons in the brainstem nucleus are damaged. In contrast, the lesion site in central palsy is located central to the nucleus (supranuclear lesion) in the course of the corticonuclear tract. The head and neck surgeon is mostly confronted with patients with peripheral nerve lesion. But sometimes the exact localisation of the lesion might be unclear, for instance in patients after brainstem astrocytoma surgery. The type of palsy must be clarified in front of reconstruction surgery as any kind of direct facial nerve reconstruction is not effective in patients with central palsy.

From the functional point of view two different situations have to be distinguished: First, patients without any sign of facial nerve regeneration due to complete hindrance of re-sprouting of the axons proximal to the lesion site are candidates. Second, patients who have developed spontaneous axonal sprouting but a functionally hindering defective healing not compensated by central brain plasticity are also candidates for surgical rehabilitation. Defective healing without spontaneous regeneration is impossible. The most important clinical signs of facial nerve defective healing are: a) dyskinesia, i. e. abnormal mimic movements during voluntary action, b) synkinesia, i.e. involuntary synchronous mimic movements while the patient is performing another voluntary movement, and c) autoparalytic syndrome as a special form of synkinesia characterized by synkinetic activity of antagonistic muscles. Synchronous antagonistic movements are detectable using electromyography but the clinical result is a decreased or unseeable muscle activity of the intended mimic movement. Dyskinesia and synkinesia can lead to d) hyperkinesia, i.e. abnormal and much stronger mimic movement than physiologically used.

An exact classification of the individual facial palsy due to the above mentioned criteria is mandatory prior to surgical decision making. In addition, the mimic musculature itself, the cerebral cortex and the other cranial nerves have to be examined for pathologies. Westin and Zuker have developed a simple and clear classification [4]. We recommend classifying each patient to our modified version of this classification directly leading to the optimal reconstruction strategy for the individual situation (Table 1).

\section{Step-by-step preoperative evaluation}

Intention of surgical reconstruction is to restore the function of the mimic musculature as optimal as possible. Under ideal circumstances this would be restoration of the resting tone of all mimic muscles and restoration of frontal frowning with lifting of the eye brow, closure of the eye, a symmetric nasolabial fold and the ability to smile nearly symmetrically. In patients with acute palsy a standardized clinical examination including analysis of

Table 1 Classification of facial palsy and guidelines for their surgical reanimation (modified after [4])

\begin{tabular}{|c|c|}
\hline Classification & Comments \\
\hline \multicolumn{2}{|l|}{ A. Congenital } \\
\hline $\begin{array}{l}\text { A.1 syndromal } \\
\text { A.2 non-syndromal }\end{array}$ & Mostly nerve plasty not possible; cortical deficits hinder additional mimic and physical training. \\
\hline \multicolumn{2}{|l|}{ B. Acquired } \\
\hline $\begin{array}{l}\text { B.1 traumatic } \\
\text { B.1.1 extracranial } \\
\text { B.1.2 intracranial }\end{array}$ & $\begin{array}{l}\text { Trauma: Exact localisation of lesion site mandatory. Acute nerve reconstruction only superior to conservative } \\
\text { treatment in case of complete palsy. }\end{array}$ \\
\hline $\begin{array}{l}\text { B.2 tumourous } \\
\text { B.2.1 extracranial } \\
\text { B.2.1.1 benign }\end{array}$ & Tumour: Prognosis quoad vitam must be considered: prefer fast rehabilitation techniques. \\
\hline \multicolumn{2}{|l|}{ B.2.1.2 malignant } \\
\hline $\begin{array}{l}\text { B.2.2 intracranial } \\
\text { B.2.2.1 benign } \\
\text { B.2.2.2 malignant }\end{array}$ & $\begin{array}{l}\text { Intracranial: Reconstruction strategy without co-adaptation of the proximal facial nerve stump often the better } \\
\text { choice. }\end{array}$ \\
\hline $\begin{array}{l}\text { B.3 infectious } \\
\text { B.3.1 acute } \\
\text { B.3.2 chronic }\end{array}$ & $\begin{array}{l}\text { Infectious: Causal therapy in front, wait for reconstruction surgery after complete healing and look on remaining } \\
\text { deficits. }\end{array}$ \\
\hline $\begin{array}{l}\text { B.4 neuromuscular } \\
\text { B.4.1 Endplate region } \\
\text { B.4.2 ganglional } \\
\text { B.4.3 axonal }\end{array}$ & Neuromuscular: Domain of conservative neurologic treatment. \\
\hline
\end{tabular}


voluntary movements (frowning, eye closure, nose wrinkling, showing the teeth, dropping of the angle of the mouth, pursing the lips) amended by electromyographic (EMG) evaluation is able to detect, which peripheral nerve branches and target muscles are affected or if the complete peripheral nerve is paralysed.

\section{Important role of EMG examination}

EMG plays a central role in the evaluation of the patient (Figure 1). Muscular damage leads to alterations of the insertion potentials during needle EMG. EMG allows a prognosis on the probability of spontaneous healing [5]. In congenital palsy or in chronic palsy EMG allows an assessment, if musculature (still) is existing and to what degree and in which regions of the face spontaneous regeneration with defective healing took place. In lesions proximal to the stylomastoid foramen disturbance of the lacrimal function and taste, or hyperacusis can be observed. In patients with regeneration and defective healing the clinical examination together with EMG allow the physician to evaluate the severity of dyskinesia, synkinesia, and autoparalytic syndrome [6].

\section{Magnetic resonance imaging}

Magnetic resonance imaging (MRI) is preferred method of choice in order to localize a lesion of the facial nerve in the brainstem, the cerebellopontine angle and in the intratemporal course of the nerve [7]. MRI is much more accurate than classical topodiagnostic methods like Schirmer's test, stapedial reflex test, and taste function testing [8]. MRI also helps to evaluate the vitality of the mimic musculature in cases with long-term denervation. Muscle atrophy and fibrosis leads to an asymmetry of muscle volume in relation to the healthy side visible in MRI [9]. Such detailed analysis accounting for the patient's wishes and the life-expectancy of a comorbid patient should lead in an individual concept for the surgical rehabilitation of each patient.

\section{Selection of the optimal surgical concept for the individual patient}

Basis for the selection of the rehabilitation technique of choice are the lesion site and the duration of palsy. Using these two parameters all surgical rehabilitation techniques can be divided in three categories (Table 2):

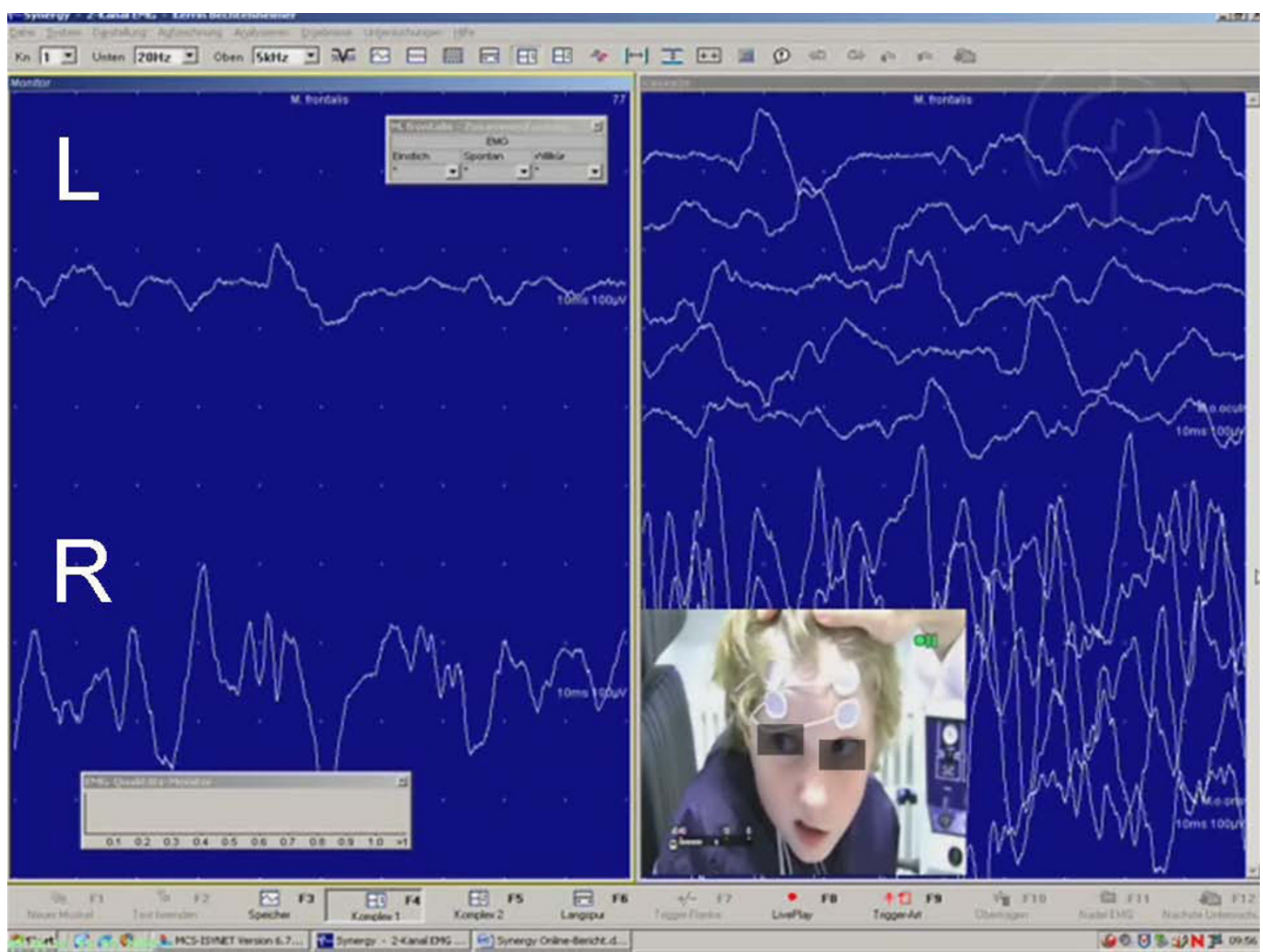

Figure 1 Eletromyographic (EMG) analysis of a child with left side facial palsy after brainstem surgery. Proof of complete loss of voluntary activity in left frontalis muscle (I) in comparison the healthy right side (r). 
Table 2 Plan by stages for facial reanimation (Modified after. [35])

\begin{tabular}{l}
\hline Surgical method \\
\hline A. Early reconstruction of extratemporal lesion \\
Step I: \\
$\begin{array}{ll}\text { A.1 Primary direct nerve suture } & \text { Comments } \\
\text { A.2 Interpositional graft } & \text { A.3. lid weight better than tarsorrhaphy } \\
\text { A.3 Upper lid weight } & \\
\text { Step II: } & \end{array}$ \\
A.4 Adjuvant measures
\end{tabular}

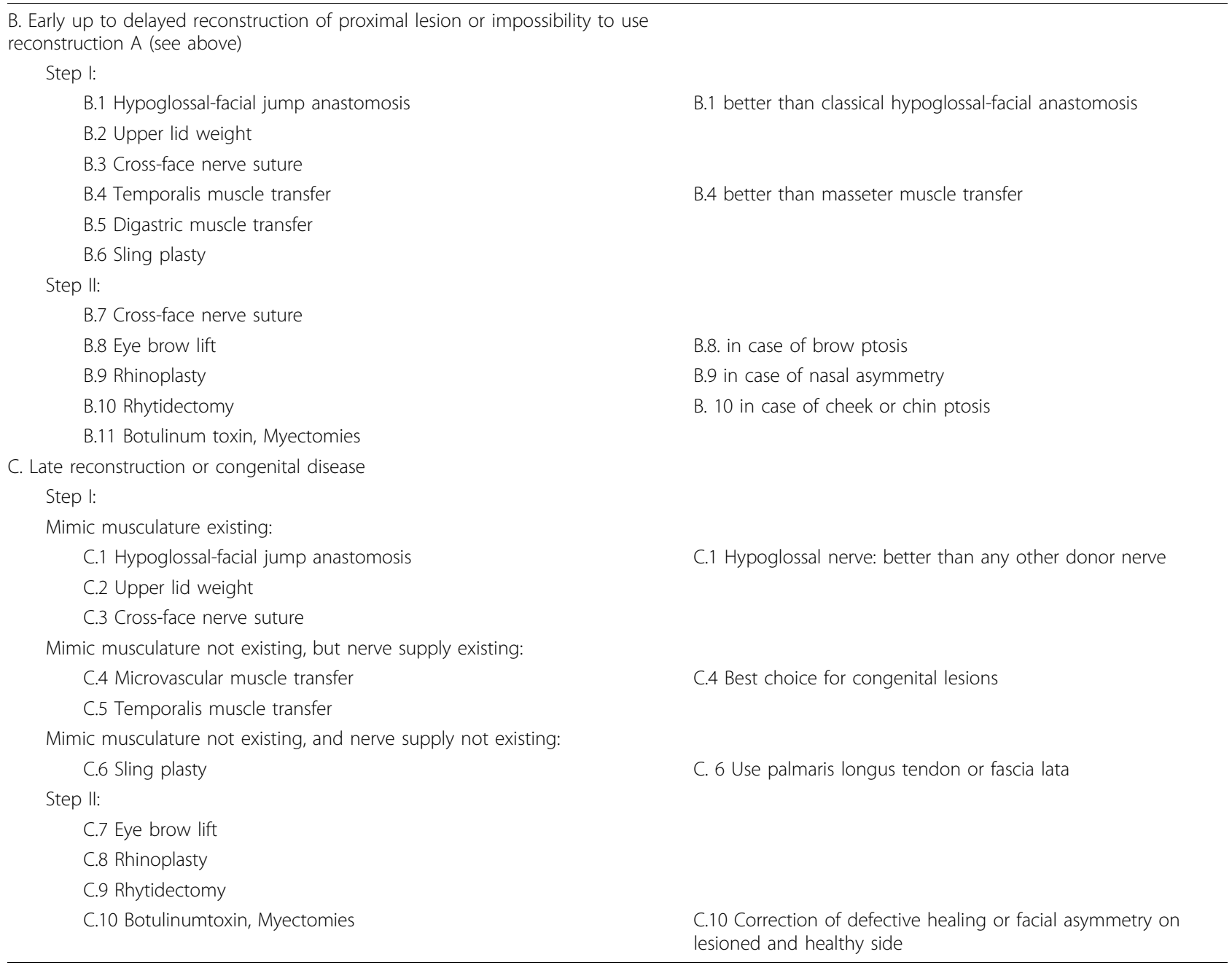

a) early extratemporal reconstruction, b) early reconstruction in case of proximal lesion or impossibility of direct extratemporal reconstruction, and c) delayed or late reconstruction or congenital facial palsy.

Early reconstruction means reconstruction within the first two months after lesion. In such a situation any nerve reconstruction will result in best possible functional recovery. Late reconstruction includes any repair 12 to 18 months after onset of the palsy. At this long denervation time irreversible atrophy and fibrosis has arisen if no regeneration occurred. Alternatively, if spontaneous but functionally insufficient regeneration emerged, defective healing has reached its final stage. Patients in-between these categories, i.e. a denervation time more than two months but less than twelve months, are difficult to categorize and must be considered individually after complete diagnostic examination.

\section{Early extratemporal facial nerve reconstruction}

In patients with traumatic facial nerve lesion (most frequently intratemporally by temporal bone fracture or extratemporally due to acts of violence) or after 
malignant tumour resection (for instance in case of parotid cancer) primary facial nerve suture should be performed as fast as possible. In tumour patients it should be done directly in the same session with tumour resection to get the best results [3]. On the other hand, a good preoperative assessment is extremely important especially in polytrauma cases. In such cases, assessment is often limited to imaging techniques, and judgement of severity of the nerve lesion due to inspection or exploration. Eventually, the recovery of consciousness or the therapy of life-threatening injuries has to be awaited.

\section{Direct facial-facial nerve suture}

In the first two months after trauma the nerve stumps can normally be dissected without hindering scar formation and best possible functional results can be achieved [6]. A direct co-adaptation of the facial nerve stumps is only possible, if the stumps are sharp-edged, i.e. after direct trauma, immediately within 24 hours after onset of the lesion.

\section{Facial nerve interpositional graft}

Later, when the nerve stumps have to be freshened or if a gap of more than $1 \mathrm{~cm}$ is observed, an interpositional graft is needed to guarantee a tension-free nerve suture [3].

Well-proven donor nerves are the greater auricular nerve and the sural nerve. The use of biodegradable nerve tubes as alloplastic alternative can not be recommended for regular use as to date only case reports on their application are published [10].

\section{Hypoglossal-facial-jump-nerve anastomosis}

Particularly after tumor resection the extratemporal resection defect can be very large in size. In such a situation a combined approach makes sense: The upper face is reconstructed with the proximal facial nerve and the lower face with a hypoglossal-facial-jump-nerve anastomosis. The separated reanimation of upper and lower face offers the advantage of prevention of synkinesia between both areas [6].

\section{Upper lid loading}

Because the first clinical signs of a successful regeneration do not occur before a time of six months and the finial results even needs twelve to 18 months, nerve suture is often combined with static reanimation of the eye closure using a upper lid weight [11,12]. If lid weight is not effective, the first alternative is a palpable spring. This surgery is typically performed by an ophthalmologist [13]. If the lower lid is suspended due to loss of facial tone, it is recommended to combine upper eye lid surgery with a lower lid plasty [14].

\section{Dynamic muscle transfer}

An alternative technique for the restoration of eye closure is to use a dynamic temporalis muscle plasty [15]. In individual cases, it could be reasonable to reanimate the angle of the mouth with a dynamic muscle plasty, too. But the surgeon has to take care not to injure the very thin facial nerve branches entering the orbicularis oris muscle. If the patient wishes a very fast solution or if life expectancy is low, a dynamic muscle plasty can also be performed as a single procedure without nerve reconstruction. Here, the temporalis muscle or the masseter muscle is used for perioral reconstruction in combination with upper lid weight for eye restoration [16]. Informed consent is necessary that the geometrical vectors of this kind of muscle plasties are limited. Muscle plasties only allow a few restored movements. A digastric muscle plasty is indicated for restoration of the depressor of the corner of the mouth in cases of isolated palsy of the marginal mandibular branch or congenital aplasia of the depressor anguli oris muscle [17].

\section{Sling plasties}

Even a dynamic muscle plasty can be technically impossible in cases of extended tumour surgery. As third choice static slings are part of the surgical arsenal. Slings allow restoration of the resting tone and improvement of facial asymmetry at rest in direction of the inserted sling. Autologic material like fascia lata or the tendon of the palmaris longus muscle is first choice in front of alloplastic material. Complications, especially wound healing problems, are seen more frequently with alloplastic material [18].

\section{Early reconstruction in case of intratemporal, more proximal lesion or facial nerve lesion or no possibility for extratemporal reconstruction}

For lesion of the facial nerve proximal to the stylomastoid foramen, especially in lesions proximal to the tympanic segment, it has to be proven carefully if nerve reconstruction with the proximal facial nerve still is first choice, or if a cross-nerve suture should be chosen instead. If an intratemporal facial nerve reconstruction is planned, an entire graft leads to better functional results than a partial graft (with the idea to preserve remaining intact nerve fibres) [19].

In general, the functional results in case of proximal facial nerve lesions seem to be better after cross nerve suture using a new motor nerve source than a far proximal nerve graft [6]. Anyway, both methods are functionally better than any elaborate intratemporal re-routing or even an intra-extracranial re-routing. 
Role of hypoglossal-facial-jump-nerve anastomosis in this setting

First choice for cross-nerve suture is the hypoglossalfacial jump nerve anastomosis (Figure 2 and 3 ). The classical type of hypoglossal-facial nerve anastomosis using the entire proximal hypoglossal nerve should be avoided nowadays. Classical hypoglossal-facial nerve anastomosis leads to unpleasant long-term sequelae, because the unilateral tongue atrophy produces permanent speech and swallowing problems. The hypoglossal-facial jump nerve anastomosis using only part of the hypoglossal nerve avoids tongue atrophy and the success rate is comparable to the classical type. Hyperkinesia, often seen after the classical technique, is avoided by the jump technique, because less nerve fibres regenerate to the periphery.

Several modifications of the hypoglossal-facial jump nerve anastomosis are described. Mostly used are a sideto-end nerve suture at the side of the proximal hypoglossal nerve and an end-to-end nerve suture to the distal facial nerve using a nerve graft in-between the hypoglossal and facial nerve. The hypoglossal nerve is incised to about $30 \%$. Thereby, the nerve opens itself wedge-shaped to house the graft for the end-to-side nerve suture. Rarely, it is possible to bring together hypoglossal and facial nerve tensionless without using an interpositional graft. Other donor nerves for cross-

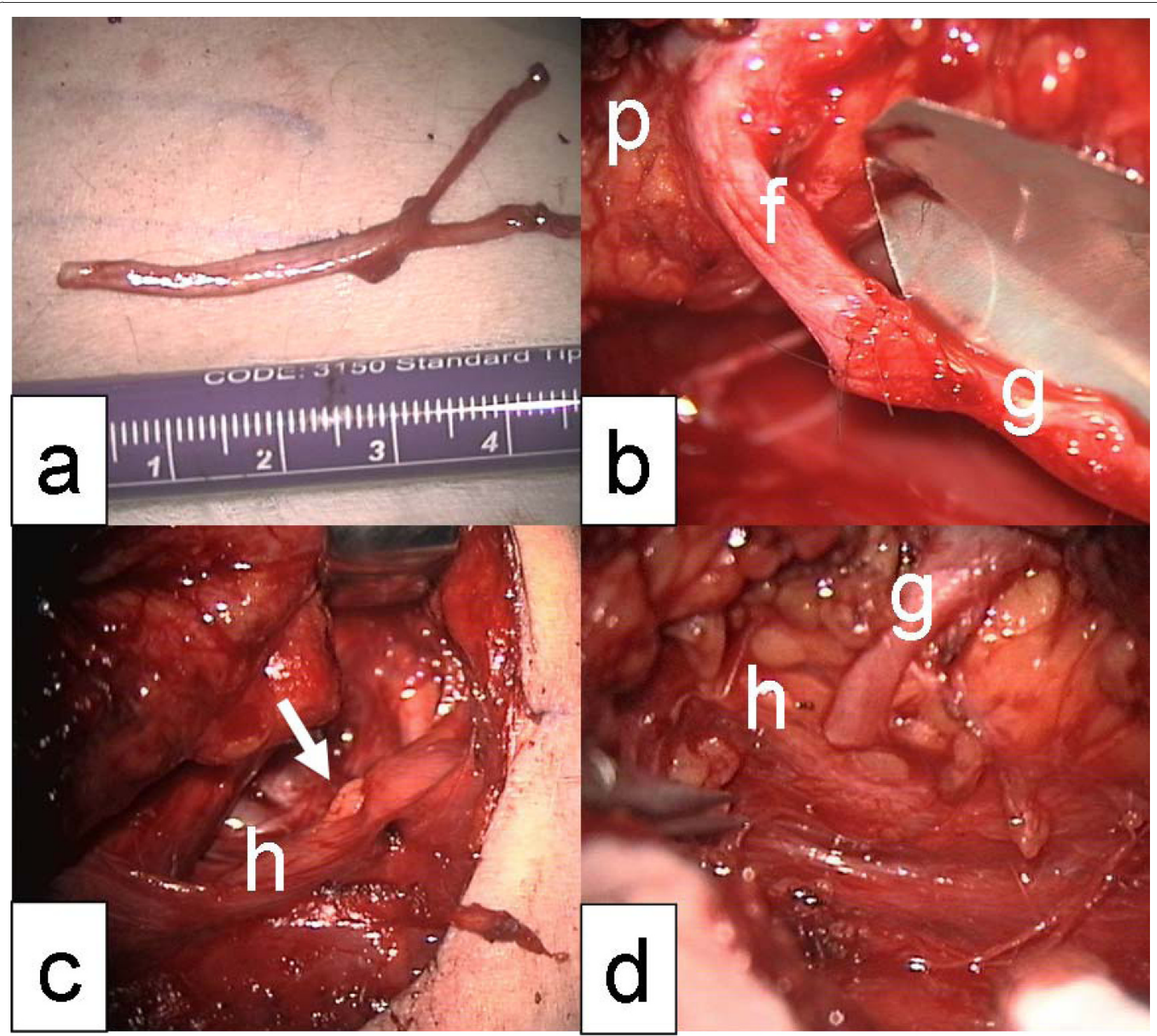

Figure 2 Hypoglossal-facial jump nerve anastomosis. a: Harvest of the greater auricular nerve as interpositional graft; b: End-to-end nerve suture of the graft $(g)$ to the peripheral facial nerve ( $f$ ); $p$ = parotid gland; $c$ : incision (arrow) of the hypoglossal nerve (h); d: end-to-side nerve suture between hypoglossal nerve $(h)$ and the graft $(g)$. 


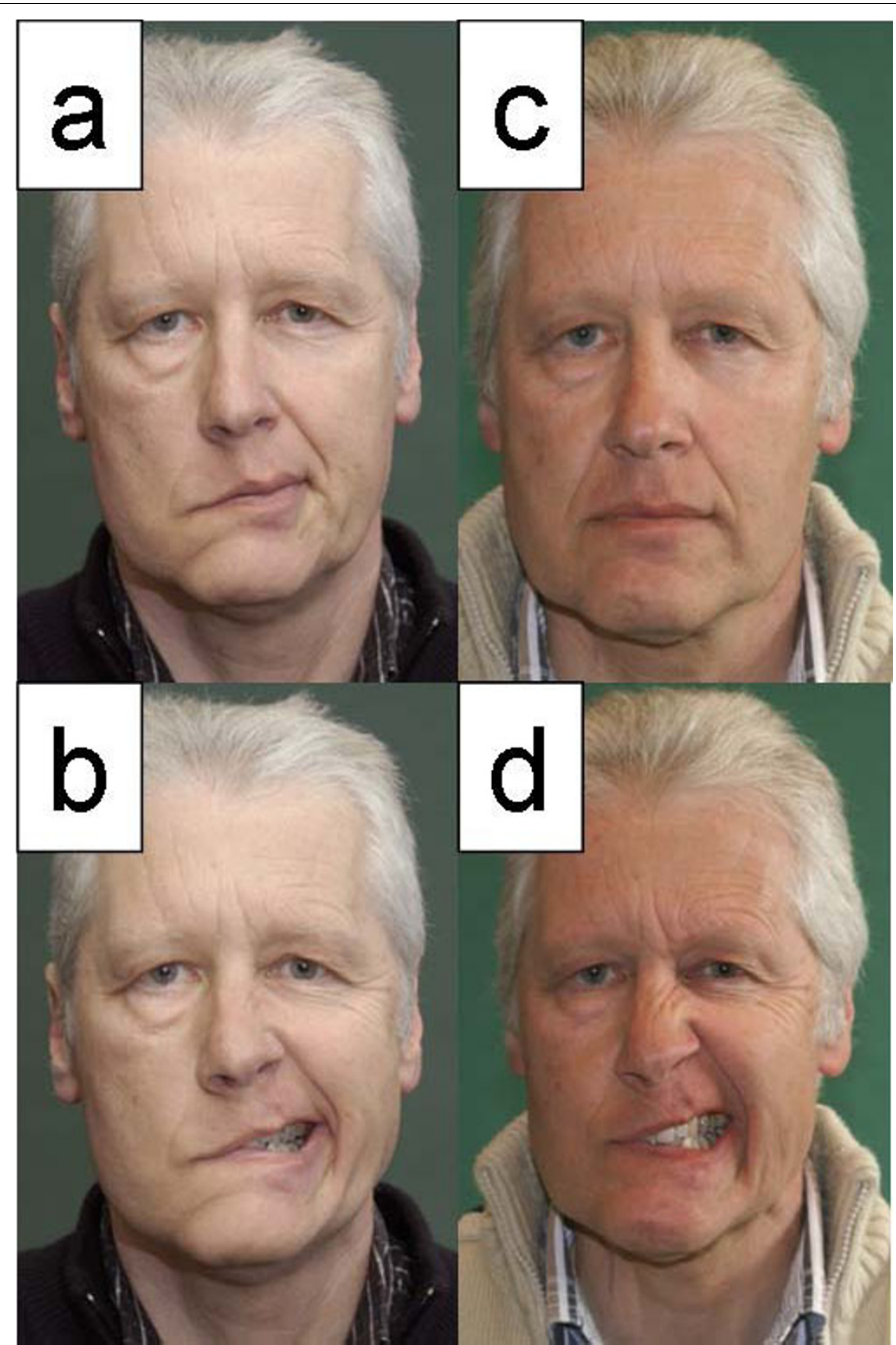

Figure 3 a, b: Patient with complete facial palsy 5 months after vestibular schwannoma surgery; c, d: Same patient 2 years after hypoglossal-facial jump nerve anastomosis. Pictures taken at rest $(a, c)$ and during exposure of the teeth $(b, d)$.

nerve suture (motoric trigeminal nerve, accessory nerve, parts of the cervical plexus, ansa nervi hypoglossi) cause more morbidity in the donor region and show less satisfactory results $[20]$.

\section{Cross-face facial nerve suture}

The best alternative to hypoglossal-facial jump nerve anastomosis is a cross-face facial nerve suture:
Peripheral facial nerve branches distal to the parotid gland are dissected on the contralateral healthy side. Even when electrostimulation is used to select two to four nerve branches to restore a selective symmetrical reinnervation of the ipsilateral lesioned side some additional palsy on the healthy side has to be accepted. To create a balance between these two aspects is difficult. The branches must be cut as distal as possible to 
minimize weakness on the healthy side. Long and several interpositional grafts are needed. Therefore, the suralis nerve is best choice. The suralis nerve is divided into several pieces. These pieces are pulled through the midface from the healthy to the lesioned side. The sural nerve grafts are sutured end-to-side to the facial nerve donor branches on the healthy side and end-to-end to selected peripheral facial nerve branches or to the main facial nerve trunk on the lesioned side[20].

Of course, depending on the individual situation, all kind of muscle plasties and sling procedures described above belong to the reanimation repertoire also in the situation of an early reconstruction in case of intratemporal lesion, more proximal facial nerve lesion or no possibility for extratemporal reconstruction.

\section{Late facial nerve reconstruction or congenital facial palsy}

Beginning with a denervation time of six months or more, a strong vital motor nerve is needed to reanimate the mimic musculature. A hypoglossal-facial jump nerve anastomosis provides acceptable results up to about two years after onset of the lesion [6]. It should be kept in mind that the best results are reached within 2 months after onset of the lesion. A denervation time of six to twelve months guarantees at least satisfactory results. In case of longer denervation time the vitality of the mimic musculature has to be examined thoroughly. Age and comorbidity have influence on the velocity of muscle atrophy and fibrosis. In patients with a denervation time longer than two years, a nerve plasty without muscle transfer cannot be recommended on a regular basis. If a nerve reconstruction technique is chosen, the patient has to be informed that it takes six months on average before first signs of the muscle reinnervation are visible.

\section{Modifications of the cross-face facial nerve suture}

If a cross-face facial nerve suture is chosen, even more time is needed because the grafts and therefore the distance to be reinnervated are much longer. To overcome this situation, the facial musculature of the lesioned side can be reanimated additionally by a so called babysitter procedure: Parallel to the cross-face surgery the facial musculature is reanimated by a hypoglossal-facial jump nerve anastomosis [21]. Recently, the babysitter procedure has also been described using the masseteric branch of the trigeminal nerve [22]. If the denervation time is longer than 6 months the proceeding fibrosis of the peripheral facial nerve could hinder the direct connection of the cross-face nerve suture to the target musculature. In such a situation, a different, two-step procedure is necessary: Nine to twelve months after the first step, when the nerve grafts are completely passed by the regrowing axons, the distal side of the grafts are connected to a free muscle transplant on the lesioned side (see below). A single step procedure, i.e. suture of the cross-face interpositional grafts and free muscle transfer at the same time in one surgical session, cannot be recommended as standard procedure as only limited data is published on this technique [23,24].

\section{Free muscle transfer}

Free microvascular muscle transfer in combination with cross-face nerve suture is therapy of choice in patients with congenital facial nerve palsy (for instance in children with Moebius syndrome). Here, often the nerve and the mimic musculature do not exist [25]. The most frequent muscles used are the gracilis muscle and the pectoralis minor muscle $[15,26]$. In case of bilateral congenital palsy the reanimation of the free muscle transplant can be restored with bilateral hypoglossal-facial jump nerve anastomosis.

\section{Dynamic muscle transfer after long-term denervation}

Especially in adult patients after tumor surgery, the use of dynamic muscle transfer (see above) is a good alternative to elaborate nerve reconstructions.

\section{Adjuvant measures}

Twelve to 24 months have to be awaited for the first reanimation sign and later the complete reinnervation of the face after any kind of nerve surgery. Many patients need additional small surgery to correct smaller complaints due to the chronic palsy and the reanimation surgery. The patients should already be informed about this fact in front of any surgery during the planning phase.

\section{Botulinum toxin therapy}

Dyskinesia and synkinesia as result of effective nerve regeneration can be reduced effectively by botulinum toxin injections (Figure 4) [27]. The reversibility of the botulinum toxin effect allows an individual adoption of necessary treatment. Since the introduction of botulinum toxin for this indication, definitive selective myectomies or neurectomies are no longer necessary. These irreversible and rough procedures should only be discussed if botulinum toxin is not effective. In facial areas with permanent weakened movements the asymmetry to the contralateral facial side is even amplified by overuse of the contralateral healthy side. In such a case, botulinum toxin can also be applied on the healthy side to reduce the muscle movements in the overused mimic areas. On the healthy side, botulinum toxin is most often used to reduce the function of the depressor anguli oris muscle [28]. 


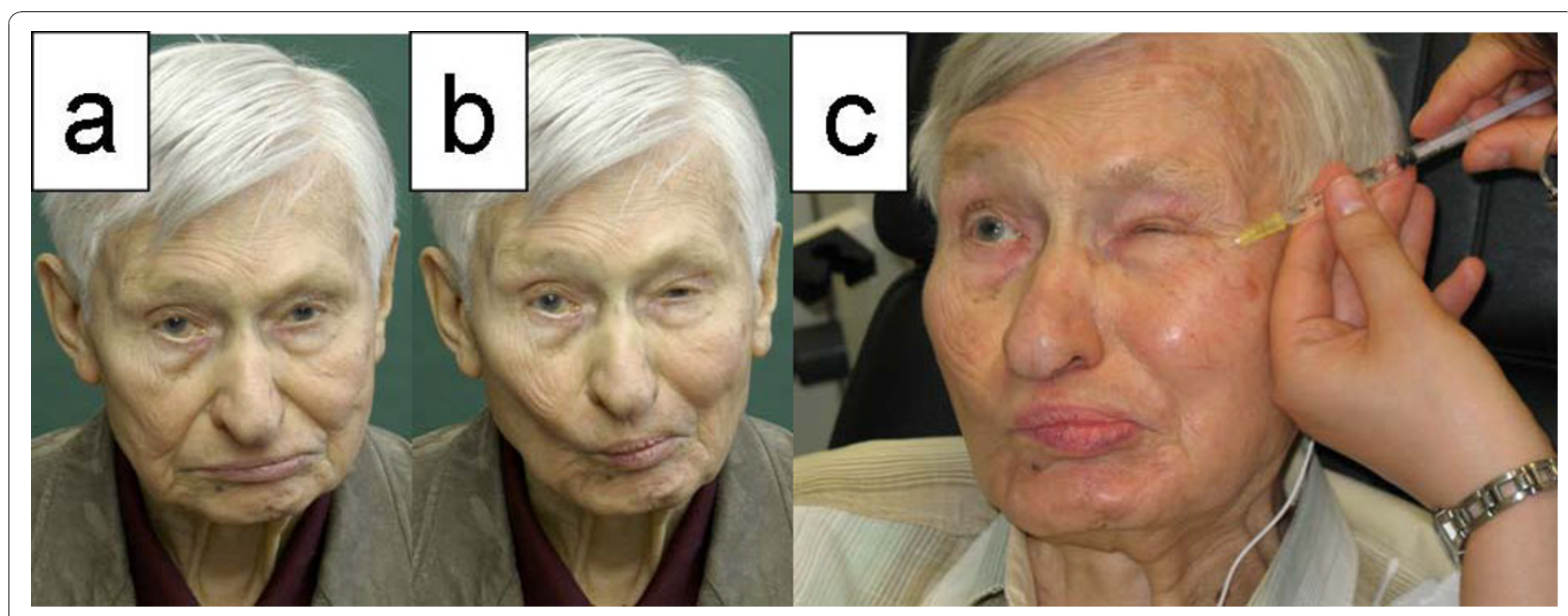

Figure 4 Patient with oro-ocular synkinesia after severe Bell's palsy of left side; Pictures taken at rest (a) and with pursed mouth and involuntary synkinetic closure of the left eye (b). Treatment of the synkinesia with botulinum toxin injection into the orbicularis oculi muscle (c)

\section{Mimic therapy and physical therapy}

Mimic therapy should start at best when the first reinnervation signs are visible by EMG or are at least when reinnervation is clinically visible in the mimic musculature after nerve reanimation surgery. Before, mimic therapy only is frustrating for the patients, because it will not result in voluntary movements. In case of hypoglossal-facial jump nerve anastomosis, the training must focus first on intended tongue movements to induce facial mimic movement. The patient will learn which

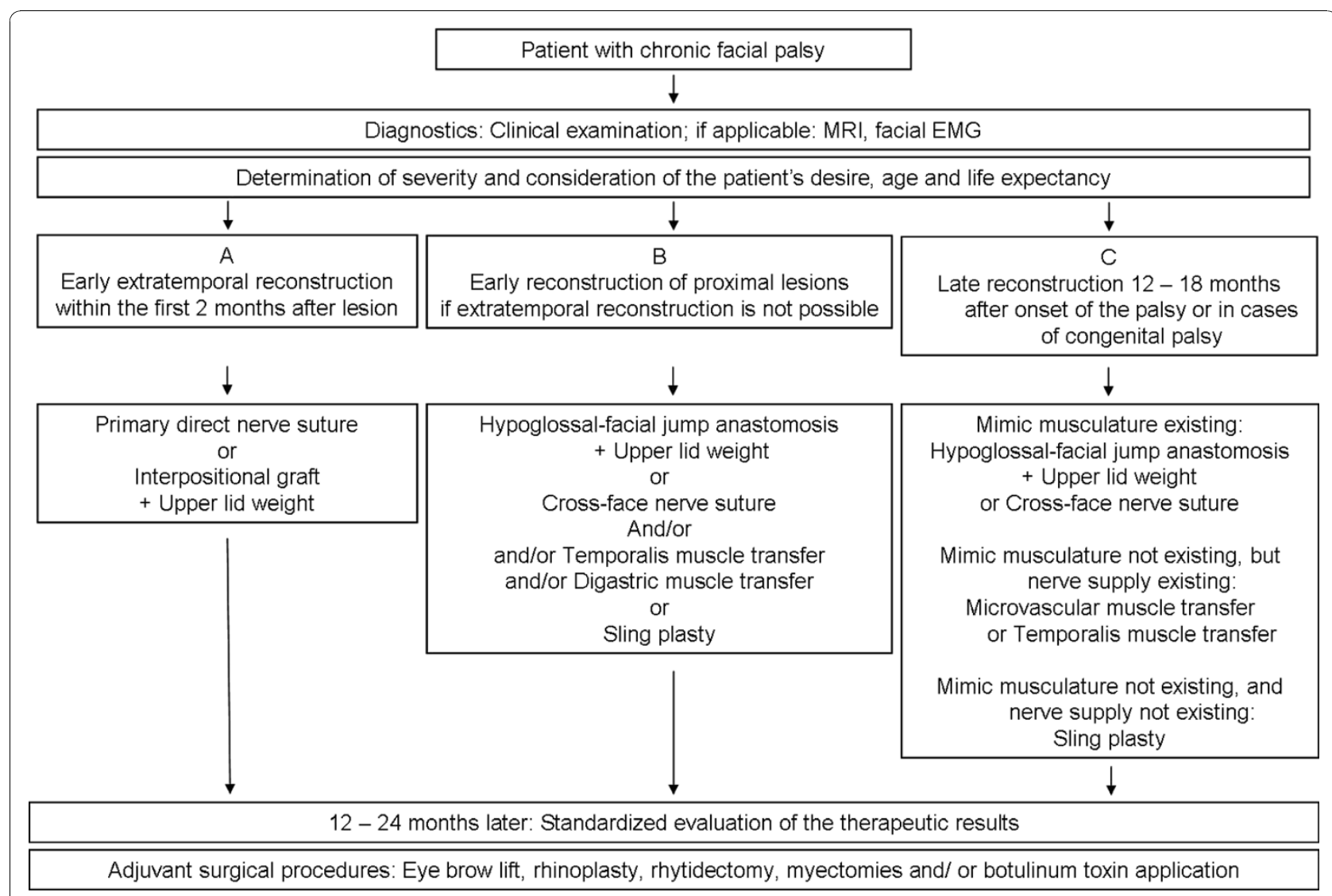

Figure 5 Summarizing schematic algorithm of the different possibilities of facial nerve reconstruction. 
kind of intended tongue movements lead to which kind of facial movement. With time, the patient will move his face without thinking on tongue movements anymore.

Systematic controlled studies on the role of physical therapy and also on the role of electrostimulation therapy are lacking $[29,30]$. It is imaginable that physical therapy could help to reduce the degree of muscle atrophy in the first time after nerve suture to bridge the time before the regrowing axons have reached the mimic musculature. In patients with muscle transfer physical therapy could start after wound healing and help the patient to train the transferred muscle for his new function [31].

\section{Evaluation of the surgical results}

Most clinical studies on the results of facial nerve reconstruction use (beside photographs) the House-Brackmann grading system, although this system was only developed to classify acute facial palsy. Assessment of defective healing is not part of this classification system. Therefore, other systems including the assessment of defective healing are more suitable for evaluation of the surgical results. Such systems are: Stennert Index, Sydney system or the Sunnybrook system $[6,32,33]$. Even better are objective observer-independent measurement tools like video-based semiquantitative measurement systems. But up to now, these system has not become part of clinical routine [15]. Beside the functional evaluation, the assessment should nowadays also include the measurement of quality of life after facial reconstruction surgery [34].

\section{Conclusion}

Head and neck surgeons faced with acute or chronic facial palsy demanding surgical repair need a broad spectrum of surgical tools in order to ensure optimal treatment of the patient. Following the diagnostic recommendations and the classification presented in this review may help to find the optimal strategy of modern facial nerve rehabilitation for the individual patient with severe facial palsy (Summary in Figure 5).

\section{Consent}

It is stated that informed written consent was obtained for publication of the patients images.

\section{Abbreviations}

EMG: electromyography; MRI: Magnetic resonance imaging.

\section{Authors' contributions}

The authors issued the whole manuscript. All three authors have read and approved the final manuscript.

\section{Competing interests}

The authors declare that they have no competing interests.
Received: 9 August 2010 Accepted: 1 November 2010

Published: 1 November 2010

\section{References}

1. Sullivan FM, Swan IR, Donnan PT, Morrison JM, Smith BH, McKinstry B, Davenport RJ, Vale LD, Clarkson JE, Hammersley V, et al: Early treatment with prednisolone or acyclovir in Bell's palsy. N Engl J Med 2007, 357:1598-1607.

2. Odebode TO, Ologe FE: Facial nerve palsy after head injury: Case incidence, causes, clinical profile and outcome. J Trauma 2006, 61:388-391.

3. Iseli TA, Harris G, Dean NR, Iseli CE, Rosenthal EL: Outcomes of static and dynamic facial nerve repair in head and neck cancer. Laryngoscope 2010, 120:478-483

4. Westin LM, Zuker R: A new classification system for facial paralysis in the clinical setting. J Craniofac Surg 2003, 14:672-679.

5. Grosheva M, Wittekindt C, Guntinas-Lichius O: Prognostic value of electroneurography and electromyography in facial palsy. Laryngoscope 2008, 118:394-397.

6. Guntinas-Lichius O, Streppel M, Stennert E: Postoperative functional evaluation of different reanimation techniques for facial nerve repair. AmJSurg 2006, 191:61-67.

7. Veillon F, Taboada LR, Eid MA, Riehm S, Debry C, Schultz P, Charpiot A: Pathology of the facial nerve. Neuroimaging Clin N Am 2008, 18:309-320, x

8. Guntinas-Lichius O, Sittel C: [Diagnostics of diseases and the function of the facial nerve]. Hno 2004, 52:1115-1130, quiz 1131-1112.

9. Kaylie DM, Wax MK, Weissman JL: Preoperative facial muscle imaging predicts final facial function after facial nerve grafting. AJNR AmJNeuroradiol 2003, 24:326-330.

10. Lohmeyer J, Zimmermann S, Sommer B, Machens HG, Lange T, Mailander $P$ : [Bridging peripheral nerve defects by means of nerve conduits]. Chirurg 2007, 78:142-147.

11. Golio D, De Martelaere S, Anderson J, Esmaeli B: Outcomes of periocular reconstruction for facial nerve paralysis in cancer patients. Plast Reconstr Surg 2007, 119:1233-1237.

12. Schrom T, Buchal A, Ganswindt S, Knipping S: Patient satisfaction after lid loading in facial palsy. Eur Arch Otorhinolaryngol 2009, 266:1727-1731.

13. Demirci $H$, Frueh BR: Palpebral spring in the management of lagophthalmos and exposure keratopathy secondary to facial nerve palsy. Ophthal Plast Reconstr Surg 2009, 25:270-275.

14. Razfar A, Afifi AM, Manders EK, Myers EN, Johnson JT, Ferris RL, Deleyiannis FW: Ocular outcomes after gold weight placement and facial nerve resection. Otolaryngol Head Neck Surg 2009, 140:82-85.

15. Frey M, Michaelidou M, Tzou CH, Pona I, Mittlbock M, Gerber H, Stussi E: Three-dimensional video analysis of the paralyzed face reanimated by cross-face nerve grafting and free gracilis muscle transplantation: quantification of the functional outcome. Plast Reconstr Surg 2008, 122:1709-1722

16. Michaelidou M, Tzou CH, Gerber H, Stussi E, Mittlbock M, Frey M: The combination of muscle transpositions and static procedures for reconstruction in the paralyzed face of the patient with limited life expectancy or who is not a candidate for free muscle transfer. Plast Reconstr Surg 2009, 123:121-129.

17. Terzis JK, Kalantarian B: Microsurgical strategies in $\mathbf{7 4}$ patients for restoration of dynamic depressor muscle mechanism: a neglected target in facial reanimation. Plast Reconstr Surg 2000, 105:1917-1931, discussion 1932-1914.

18. Skourtis ME, Weber SM, Kriet JD, Girod DA, Tsue TT, Wax MK: Immediate Gore-Tex sling suspension for management of facial paralysis in head and neck extirpative surgery. Otolaryngol Head Neck Surg 2007, 137:228-232.

19. Bento RF, Salomone R, Brito R, Tsuji RK, Hausen M: Partial lesions of the intratemporal segment of the facial nerve: graft versus partial reconstruction. Ann Otol Rhinol Laryngol 2008, 117:665-669.

20. Terzis JK, Konofaos P: Nerve transfers in facial palsy. Facial Plast Surg 2008, 24:177-193.

21. Terzis JK, Olivares FS: Long-term outcomes of free-muscle transfer for smile restoration in adults. Plast Reconstr Surg 2009, 123:877-888.

22. Faria JC, Scopel GP, Ferreira MC: Facial reanimation with masseteric nerve babysitter or permanent procedure? Preliminary results. Ann Plast Surg 2010, 64:31-34. 
23. Hayashi A, Maruyama Y: Neurovascularized free short head of the biceps femoris muscle transfer for one-stage reanimation of facial paralysis. Plast Reconstr Surg 2005, 115:394-405.

24. Biglioli F, Frigerio A, Rabbiosi D, Brusati R: Single-stage facial reanimation in the surgical treatment of unilateral established facial paralysis. Plast Reconstr Surg 2009, 124:124-133.

25. Bianchi B, Copelli C, Ferrari S, Ferri A, Sesenna E: Facial animation in children with Moebius and Moebius-like syndromes. J Pediatr Surg 2009, 44:2236-2242.

26. Terzis JK, Olivares FS: Long-term outcomes of free muscle transfer for smile restoration in children. Plast Reconstr Surg 2009, 123:543-555

27. Salles AG, Toledo PN, Ferreira MC: Botulinum toxin injection in longstanding facial paralysis patients: improvement of facial symmetry observed up to 6 months. Aesthetic Plast Surg 2009, 33:582-590.

28. Chen CK, Tang YB: Myectomy and botulinum toxin for paralysis of the marginal mandibular branch of the facial nerve: a series of 76 cases. Plast Reconstr Surg 2007, 120:1859-1864.

29. Teixeira LJ, Soares BG, Vieira VP, Prado GF: Physical therapy for Bell s palsy (idiopathic facial paralysis). Cochrane Database Syst Rev 2008, CD006283.

30. Paternostro-Sluga T, Herceg M, Frey M: [Conservative treatment and rehabilitation in peripheral facial palsy]. Handchir Mikrochir Plast Chir 2010, 42:109-114.

31. Lindsay RW, Robinson M, Hadlock TA: Comprehensive facial rehabilitation improves function in people with facial paralysis: a 5 -year experience at the Massachusetts Eye and Ear Infirmary. Phys Ther 2010, 90:391-397.

32. Coulson SE, Croxson GR, Adams RD, O'Dwyer NJ: Reliability of the "Sydney," "Sunnybrook," and "House Brackmann" facial grading systems to assess voluntary movement and synkinesis after facial nerve paralysis. Otolaryngol Head Neck Surg 2005, 132:543-549.

33. Neely JG, Cherian NG, Dickerson CB, Nedzelski JM: Sunnybrook facial grading system: reliability and criteria for grading. Laryngoscope 2010, 120:1038-1045.

34. Guntinas-Lichius O, Straesser A, Streppel M: Quality of life after facial nerve repair. Laryngoscope 2007, 117:421-426.

35. Rosson GD, Redett RJ: Facial palsy: anatomy, etiology, grading, and surgical treatment. J Reconstr Microsurg 2008, 24:379-389.

doi:10.1186/1746-160X-6-25

Cite this article as: Volk et al: Modern concepts in facial nerve reconstruction. Head \& Face Medicine 2010 6:25.

\section{Submit your next manuscript to BioMed Central and take full advantage of:}

- Convenient online submission

- Thorough peer review

- No space constraints or color figure charges

- Immediate publication on acceptance

- Inclusion in PubMed, CAS, Scopus and Google Scholar

- Research which is freely available for redistribution

Submit your manuscript at www.biomedcentral.com/submit
Ciomed Central 